\title{
DEMONSTRATIVE STUDY ON DEVELOPMENT OF A METHOD FOR REUSABLE WALL STRUCTURE MADE OF THINNED-OUT JAPANESE CEDAR- DESIGN STUDY OF ARC WOODEN HOUSE
}

\author{
Le Dieu Huyen*, Fukuda Hiroatsu, Sindemizukun Taizo, and Ochiai Takasama \\ Faculty of Environmental Engineering, The University of Kitakyushu, Kitakyushu, Japan \\ *Corresponding author (w09e0401@hibikino.ne.jp)
}

\begin{abstract}
Using wood in construction is one of the best way to reduce the emission of carbon dioxide, because wood is material that fixes carbon dioxide in the long term. Japanese cedar grows up quickly, with low price, but it has been used unpopular in construction in Japan. Because it is less intensity as construction material in comparison to other imported lumbers. We currently developed a construction method for wooden house, which was made of thinned-out Japanese cedar. This material is less intense than other lumbers. However when using this lumber to make a frame and place one by one, we use it as the main structure material. Based on this method, we developed "Design Study Arc Wooden House". In this study, we divided building construction into 2 parts. First, we used thinned-out Japanese cedar with dimension of $105 \times 105 \times 3000$, to get trapezoid frame. Each frame was arranged into a skeleton of the building. Second, we used another size, is that 30x100x3000 to complete arc-shape. By using this, we found the cedar has possibilities for new planning and has a potential value as main structure material.
\end{abstract}

Keywords: Construction Method, Wooden House, Frame, Japanese Thinned Cedar

\section{INTRODUCTION}

Using Japanese construction material such as domestic wood to construct long life span buildings is a concrete solution of solving global warming. Because wood is material that can be reused, especially recycle-base resources. Currently, $70 \%$ of wood used in Japanese construction filed are imported but with the aim to reduce carbon dioxide emission, include transportation emission, by promoting using domestic wood in construction filed is necessary. Especially, Japanese cedar grows up quickly, low price, but it is less intense than other lumbers (ex: Japanese cypress, Tsuga) [1]. Therefore we rarely use Japanese cedar in Japanese construction method recently, which use columns and beams as main constructional materials. The aim of our study is to solve out this by applying new method, i.e. using thinned-out Japanese cedar as a main constructional material such as floor, wall and roof to make a frame by putting them into a line, then we arrange those frames to get space intensely.

We have constructed experimental square frame wooden housing on the studies "Demonstrative Study on Development of a Method for Reusable Wall Structure Made of Thinned Out Japanese Cedar - Examine SelfBuilding and Construction Performance" (MITSUMOTO Akihiro, 2006) [2] and "Empirical Research on Development of Square Frame Wooden Structure of Thinned Cedar" (KUROKI Toshio, 2010) [3].

Based on these studies, we developed the current studying "design study arc wooden house". 


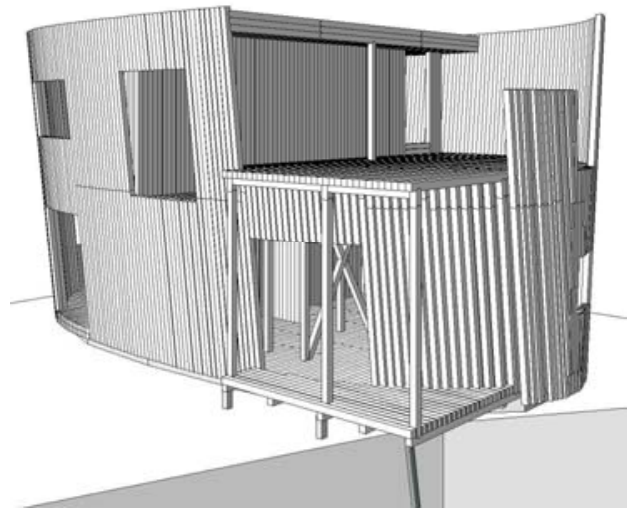

Fig. 1 View from south-east

Table 1 Outline of model

\begin{tabular}{|l|l|l|l|l|}
\hline \multirow{2}{*}{ Location } & \multicolumn{4}{|c|}{ Hiroshima city, Hiroshima prefecture } \\
\hline \multirow{2}{*}{ Area } & site & register & 1st floor & 2nd floor \\
\cline { 2 - 5 } & $543.9 \mathrm{~m}^{2}$ & $230.8 \mathrm{~m}^{2}$ & $65.4 \mathrm{~m}^{2}$ & $44.5 \mathrm{~m}^{2}$ \\
\hline Height & \multicolumn{3}{|c|}{$5.4 \mathrm{~m}$} \\
\hline Designation of Building Coverage Ratio & $12 \%$ \\
\hline \multicolumn{3}{|l|}{ Designation of floor area Ratio } & $20 \%$ \\
\hline
\end{tabular}

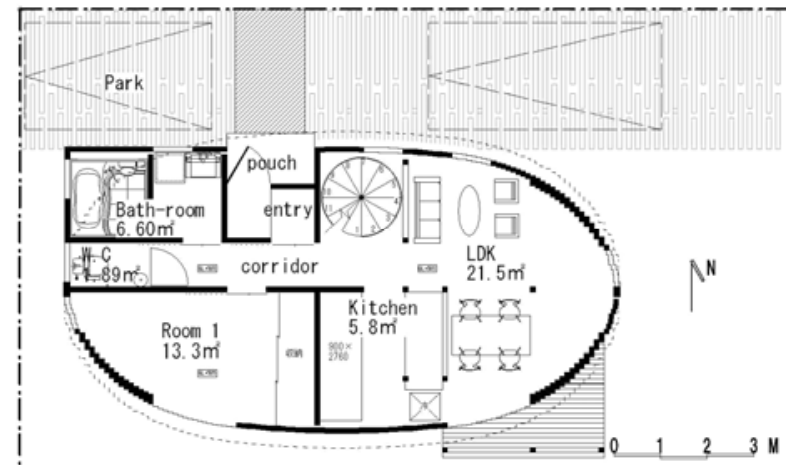

Fig. 2 1st Floor

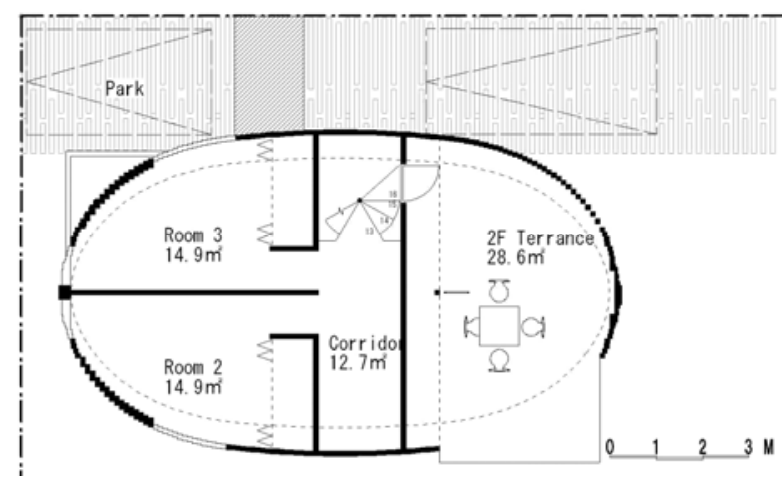

Fig. 3 2nd Floor

\section{OUTLINE OF METHODS}

We designed the house for a 4-people family. First floor include a toilet, a bathroom, a dressing and washing room in north-west and a Western style room in southern-west and living - dining - kitchen space in east. The second floor, there are 2 bedrooms. (Fig. 2, 3)

Wood in use: thinned-out Japanese cedar $105 \mathrm{~mm} \times 105 \mathrm{~mm}$, $\ell=3000 \mathrm{~mm} ; 100 \mathrm{~mm} \times 30 \mathrm{~mm}, \ell=3000 \mathrm{~mm} ; 105 \mathrm{~mm} \times 270 \mathrm{~mm}$, $\ell=3000 \mathrm{~mm} ※$ beam.

We divided building construction into 2 parts.

First, we used thinned-out Japanese cedar with dimension $105 \mathrm{~mm} \times 105 \mathrm{~mm}, \ell=3000 \mathrm{~mm}$, to set up through the $1 \mathrm{st}$ floor and 2 nd floor as a trapezoid frame. Each frame was arranged to create skeleton of building and place one by one.

Second, the ends of building (east and west) were used another size, $100 \mathrm{~mm} \times 30 \mathrm{~mm}, \ell=3000 \mathrm{~mm}$ to complete arc shape. Characteristic of this method was using length of wood to get solidity $\mathrm{V}$ shapes. This method was easier than Japanese traditional construction method.

Finishing indoor walls were used veneer board, furring strips, plaster board, finishing cloth. Finishing outdoor walls were used plaster board, asphalt left, furring strips, cedar board-lined.

This construction site was located in residential area. In the front (north side) of this site, is road with $4 \mathrm{~m}$ width and $19.87 \mathrm{~m}$ length, east side was slope. The weight of lumbers for construction was 18.5 tons. Lumbers were transported to the construction site by 4 -ton trucks and by 6 times. The quantity of unit was based on the number of frame's lumber which was transported for each time.

We designated the alphabet from $\mathrm{A}$ to $\mathrm{N}$ to each unit (from west to east of skeleton). And the units of the ends of building were designated $\mathrm{O}$ and $\mathrm{P}$. In addition, we designated the sign (i.e. 1, 2, 3 and so forth) for each frame. 


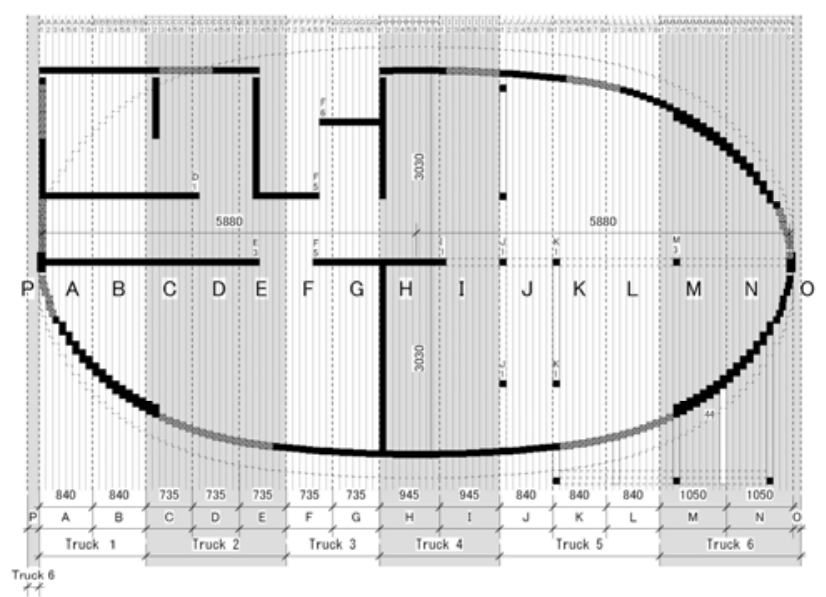

Fig. 4 Frame number

\begin{tabular}{|c|c|c|c|c|}
\hline Truck & Unit & Frame number & & \\
\hline \multirow{2}{*}{1} & $A$ ( 8 frames $)$ & A1...AS & Weight total (kg) & 3305 \\
\hline & $B$ (8 frames) & B1...BS & $105 \times 105 \times 3000$ (timber) & 275 \\
\hline \multirow{3}{*}{2} & $C(7$ frames $)$ & $\mathrm{C} 1 \ldots \mathrm{C} 7$ & Weight total (kg) & 3421 \\
\hline & $D(7$ frames $)$ & D1 ..D7 & $105 \times 105 \times 3000$ (timber) & 305 \\
\hline & $E$ (7 frames) & E1...E7 & & \\
\hline \multirow{2}{*}{3} & $F(7$ frames $)$ & F1...F7 & Weight total (kg) & 2433 \\
\hline & $\mathrm{G}(7$ frames $)$ & G1...G7 & $105 \times 105 \times 3000$ (timber) & 204 \\
\hline \multirow{3}{*}{4} & Beam & I2-I8, H2-19(2nd floor) & Weight total (kg) & 3436 \\
\hline & $\mathrm{H}$ (9 frames) & $\mathrm{H} 1 \ldots \mathrm{H} 9(\mathrm{H} 3)$ & $105 \times 105 \times 3000$ (timber) & 290 \\
\hline & I(9 frames) & $\mathrm{I} 1(\mathrm{H} 2) \ldots 19$ & $105 \times 270 \times 3000$ (timber) & \\
\hline \multirow{4}{*}{5} & Beam & $\mathrm{J} 2-\mathrm{J} 8, \mathrm{~K} 2-\mathrm{M} 22(2), \mathrm{J} 2-\mathrm{J} 7$ (2nd floor) & Weight total (kg) & 3467 \\
\hline & $\mathrm{J}$ ( \& frames) & $\mathrm{J} 1 \ldots \mathrm{J} 8$ & $105 \times 105 \times 3000$ (timber) & 285 \\
\hline & $\mathrm{K}$ ( 8 frames $)$ & K1...K\& & $105 \times 270 \times 3000$ (timber) & 7 \\
\hline & $L$ ( 8 frames) & L1...LS & & \\
\hline \multirow{5}{*}{6} & Beam & M4-N9, M4-N6 & Weight total (kg) & 2622 \\
\hline & $\mathrm{M}(10$ frames $)$ & M1...M10 & $105 \times 105 \times 3000$ (timber) & 190 \\
\hline & $\mathrm{N}(10$ frames $)$ & $\mathrm{N} 1 \ldots \mathrm{N} 10$ & $105 \times 270 \times 3000$ (timber) & 7 \\
\hline & $O(4$ frames $)$ & $01 \ldots 04$ & $105 \times 30 \times 3000$ (timber) & 94 \\
\hline & $\mathrm{P}(6$ frames $)$ & P1 ..P6 & & \\
\hline & \multirow{4}{*}{ 合計 } & \multicolumn{2}{|l|}{ Weight total (kg) } & 18608 \\
\hline & & \multicolumn{2}{|c|}{$105 \times 105 \times 3000$ (timber)(skeleton -113 frames) } & 1549 \\
\hline & & \multirow{2}{*}{\multicolumn{2}{|c|}{$\begin{array}{l}105 \times 270 \times 3000 \text { (timber) (beam) } \\
105 \times 30 \times 3000 \text { (timber) (the ends of building }-10 \text { set) }\end{array}$}} & 5 \\
\hline & & & & 94 \\
\hline
\end{tabular}

Fig. 5 Dividing transport and unit

In order to construct easily, on each timber we designated number of each timber's position on each frame. The Fig. 6 shows method's designation for the frame.

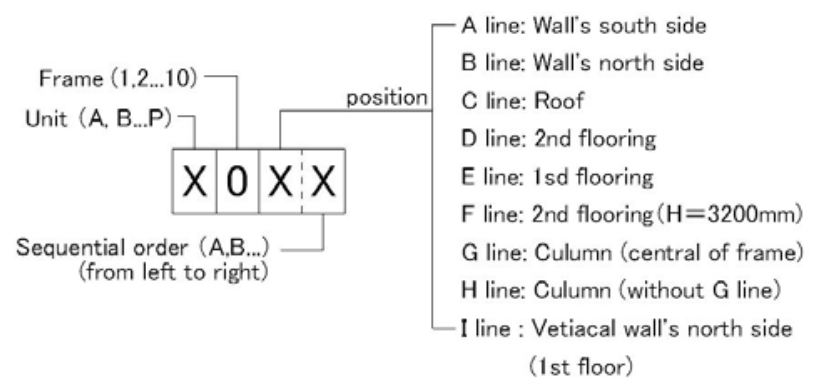

Fig. 6 Position number

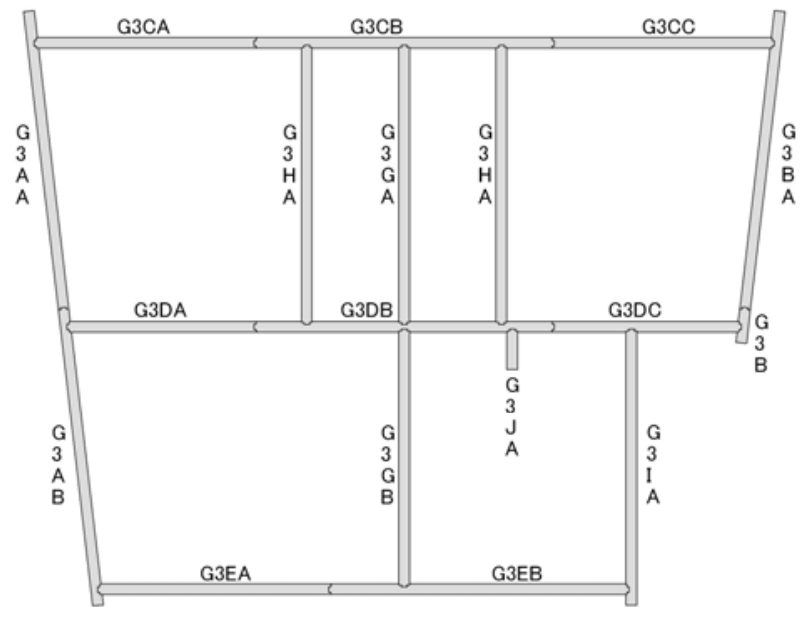

Fig. 7 Frame G3

\section{METHODS}

\subsection{To Create frame}

In this model, we applied the Japanese dovetail joint. Fig. 8 showed how to join vertical lumber such as wall or column, and horizontal lumber such as floor or roof.

(1) Column and floor

(2) Wall and floor or roof

(3) Extension lumber

(4) Other
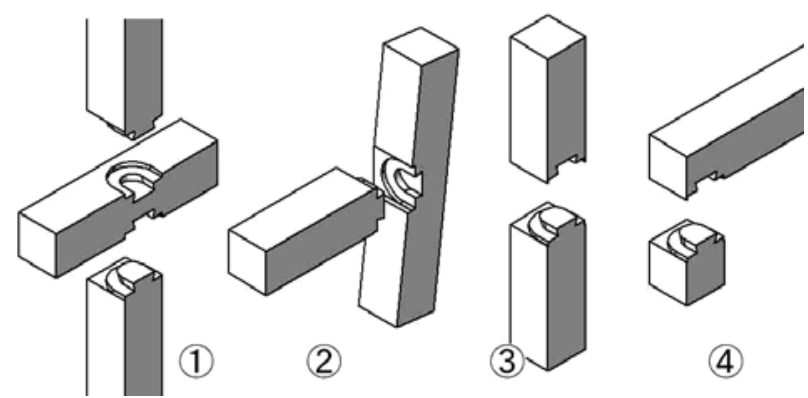

Fig. 8 Dovetail joint

Based on the dimension of design, lumbers of roof or floor were made of 2 or 3 lumbers using the Japanese dovetail connection (3) in Fig. 8. In order to avoid extension dovetail joints of roof and floor were laid in 1 row, we arranged them alternately. Fig. 9 shows joints arrangement. 


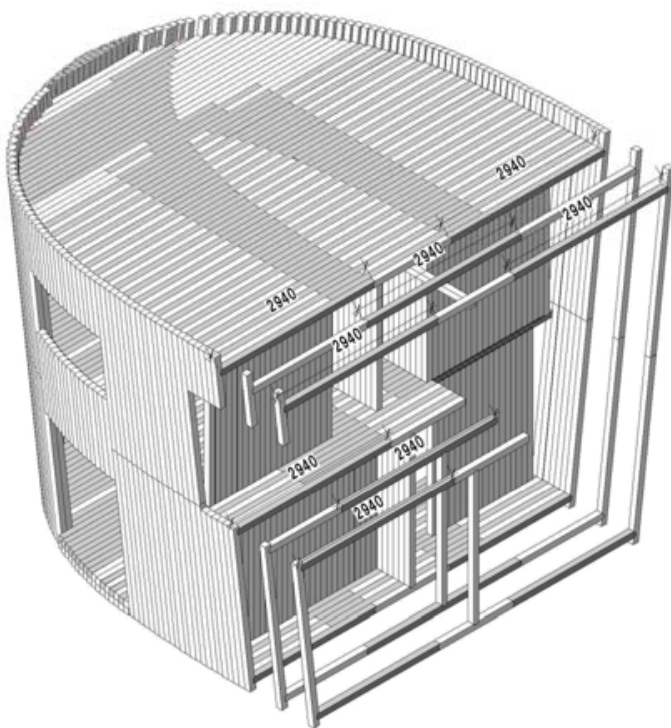

Fig. 9 Dovetail joint's arrangement

In case roof or floor were used 2 lumbers (C line of frame from $\mathrm{A} 3$ to $\mathrm{B} 7$; D line of frame from $\mathrm{A} 1$ to $\mathrm{C} 5$ and from $\mathrm{H} 2$ to $\mathrm{J} 9$ and from $\mathrm{N} 2$ to $\mathrm{N} 7$; E line of frame from A1 to D4 and from E4 to G7 and from K4 to N4), which extended lumbers had length of $\mathrm{C}$ line, B line, E line were shorter than $5850 \mathrm{~mm}$. We put lumbers with $2940 \mathrm{~mm}$ length (maximum size of a lumber) into the left of frame (CA, DA, FA, EA). Then, in the right (CB, DB, FB, EB), length of lumbers was adjusted.

In case used 3 lumbers ( $\mathrm{C}$ line of frame from $\mathrm{B} 8$ to $\mathrm{J} 8$; $\mathrm{D}$ line of frame from $\mathrm{C} 6$ to $\mathrm{J} 8$; $\mathrm{F}$ line of frame from $\mathrm{K} 1$ to $\mathrm{N} 1$; E line of frame from D5 to E3 and from H1 to L2), which extended lumbers had length of $\mathrm{C}$ line, $\mathrm{B}$ line, $\mathrm{E}$ line were longer than $5850 \mathrm{~mm}$. We put lumbers with $2940 \mathrm{~mm}$ length (maximum size of a lumber) or $1420 \mathrm{~mm}$ (one half of maximum size of a lumber) into center of line $(\mathrm{CB}, \mathrm{DB}$, FB, EB). Length of lumber of the ends of line (CA, CC; DA, DC; FA, FC; EA, EC) was adjusted.

We considered about expansion and contraction of wood in frame A1, C2, E3, H1, J1. From the column in the center ( $\mathrm{G}$ line), the distance between columns was $106 \mathrm{~mm}$ with $1 \mathrm{~mm}$ interspace.
In the east side of building, space was divided into Western room, bathroom, corridor, entry hall...by indoor walls, so these frames (1st floor and 2nd floor) were contained columns. That made intensity of these frames were stronger. (Fig. 10)

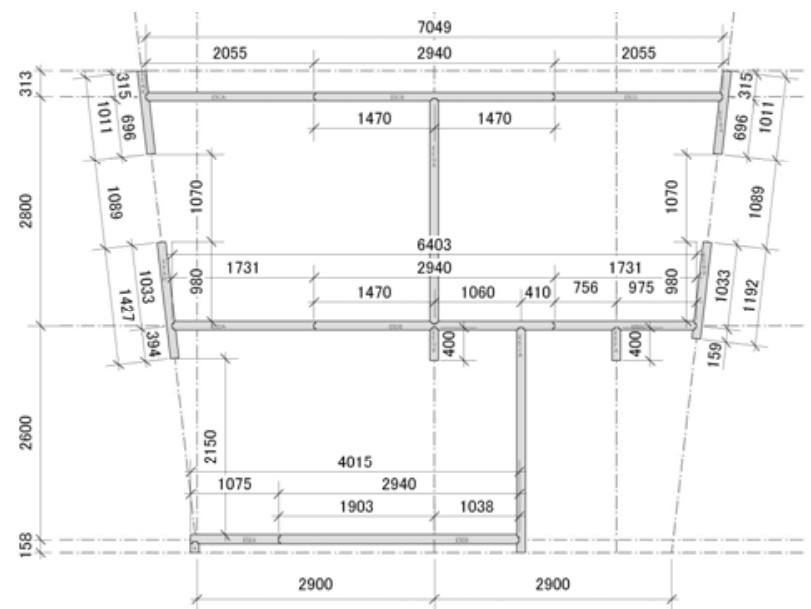

Fig. 10 E5 frame

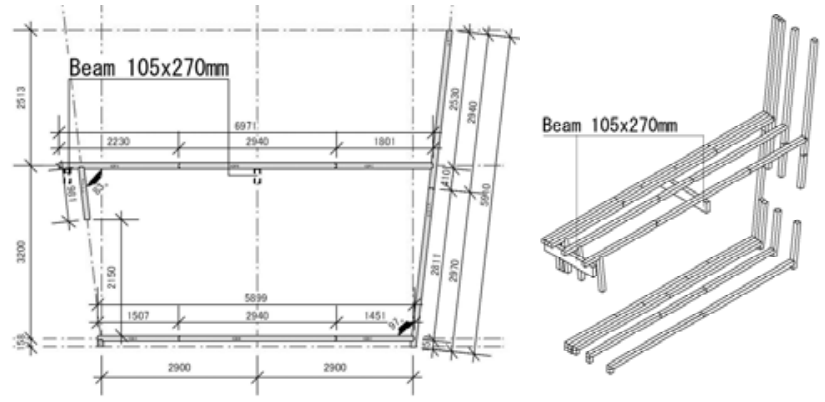

Fig. 11 K2 frame

However, west side of this building was open-space, almost frame did not contain column. So 1st floor from I2 to $\mathrm{I}$; $\mathrm{J} 2$ to $\mathrm{J} 8$; $\mathrm{K} 2$ to $\mathrm{M} 2 ; \mathrm{M} 4$ to N9, and 2nd floor from $\mathrm{H} 2$ to I9, we used thinned out Japanese cedar with dimension $105 \mathrm{~mm} \times 105 \mathrm{~mm}$ such as beams. (Fig. 11)

In frames from A1 to $\mathrm{C} 2$; M3 to N10, outdoor wall's thickness was became slim (because building were arc shape). We considered about indoor thermal environment, also the ends of skeleton was become stronger, we used 2 lumbers for A line and B line. (Fig. 12, 13) 


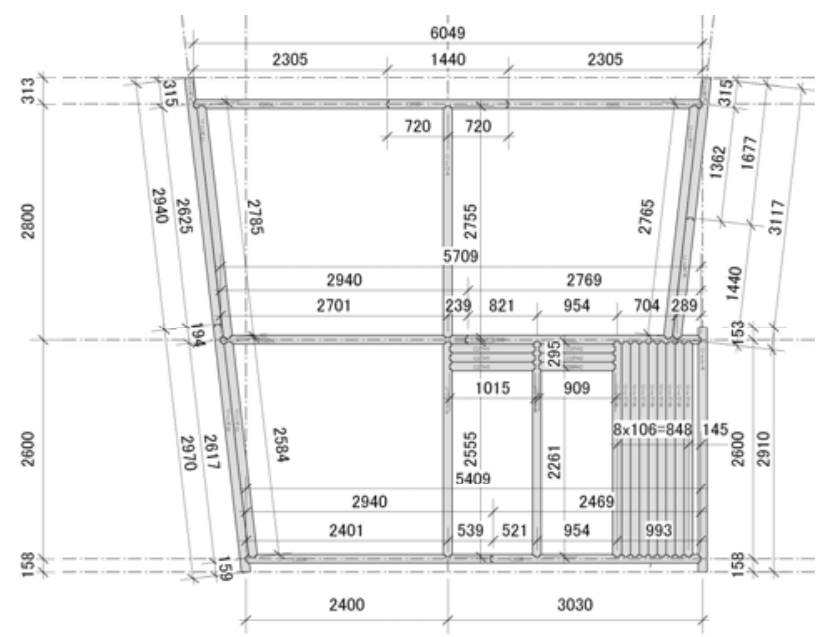

Fig. 12 C2 frame

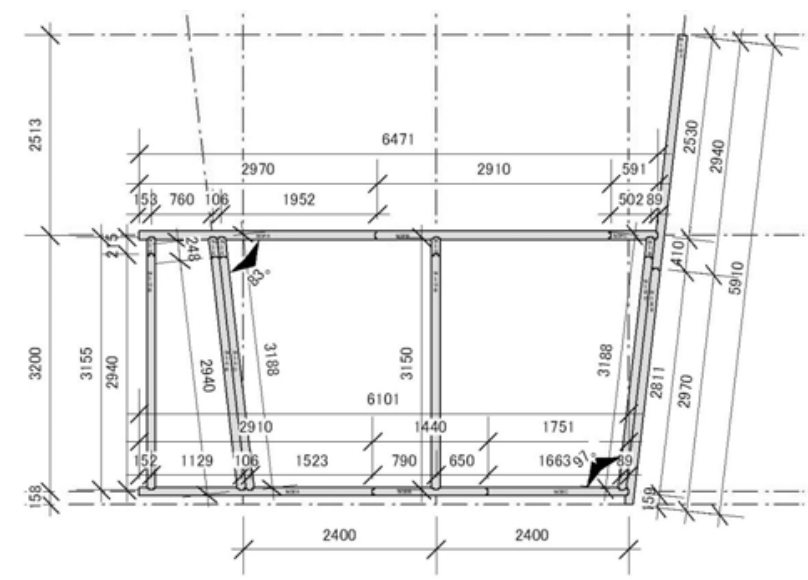

Fig. 13 M3 frame
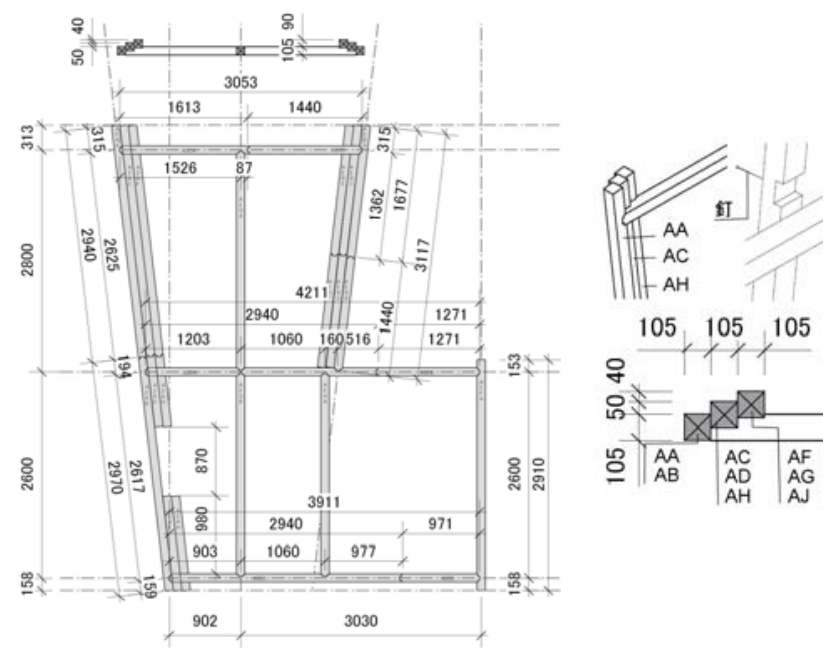

Fig. 14 A3 frame
In frames $\mathrm{A} 2, \mathrm{~A} 3, \mathrm{~N} 8, \mathrm{~N} 9$, We used 3 lumbers for $\mathrm{A}$ line and $\mathrm{B}$ line. (Fig. 14)

\subsection{To create units}

Each unit contained around 7 - 10 frames. We used joist screws $1=150 \mathrm{~mm}$ with distance around $700 \mathrm{~mm}$ to connect 2 frames. We arranged joist crews alternately. (Fig. 15, 16)

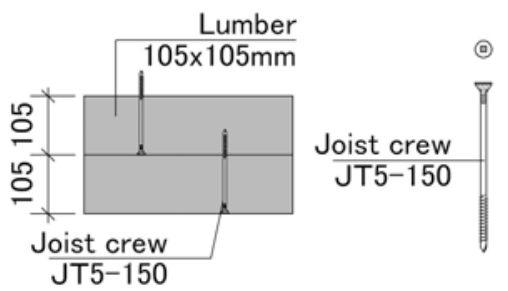

Fig. 15 Connect unit

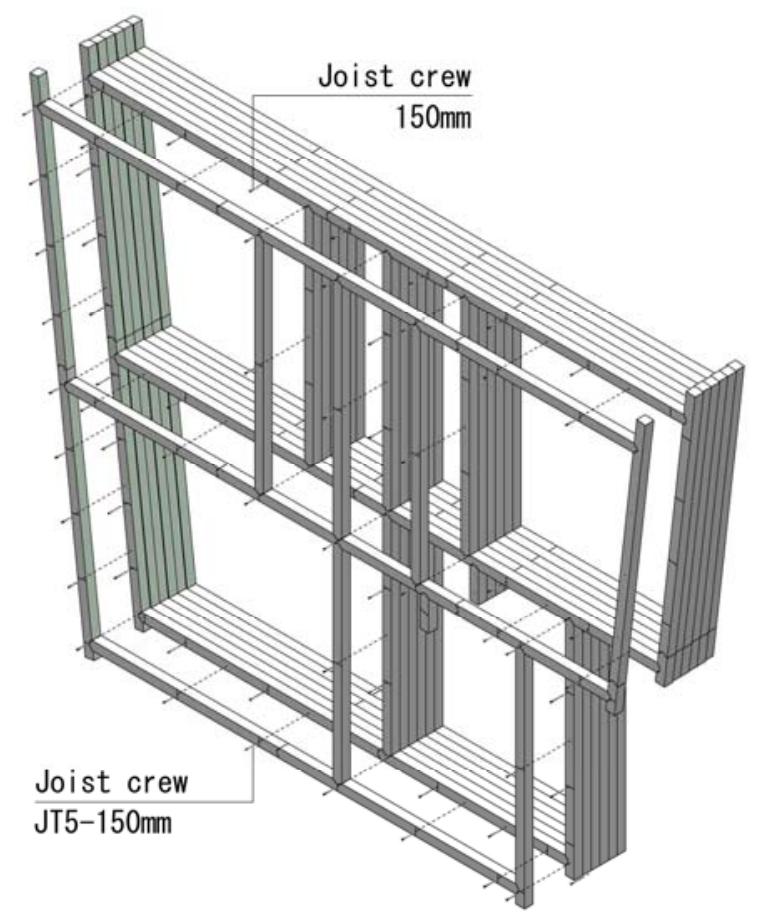

Fig. 16 Unit $\mathrm{G}$

There were 2 options regarding skeleton construction order.

1. To construct skeleton from center of building (unit $\mathrm{H}$ ) to the ends (unit $\mathrm{A}$ and unit $\mathrm{N}$ ). The advantage of this option is that can adjust the symmetrization easily. 
2. To construct skeleton from west side (A unit) to east side (Unit N). This option is easy to carry out, but we have to check the degree of arc 10 frames/1time. (Fig. 17)

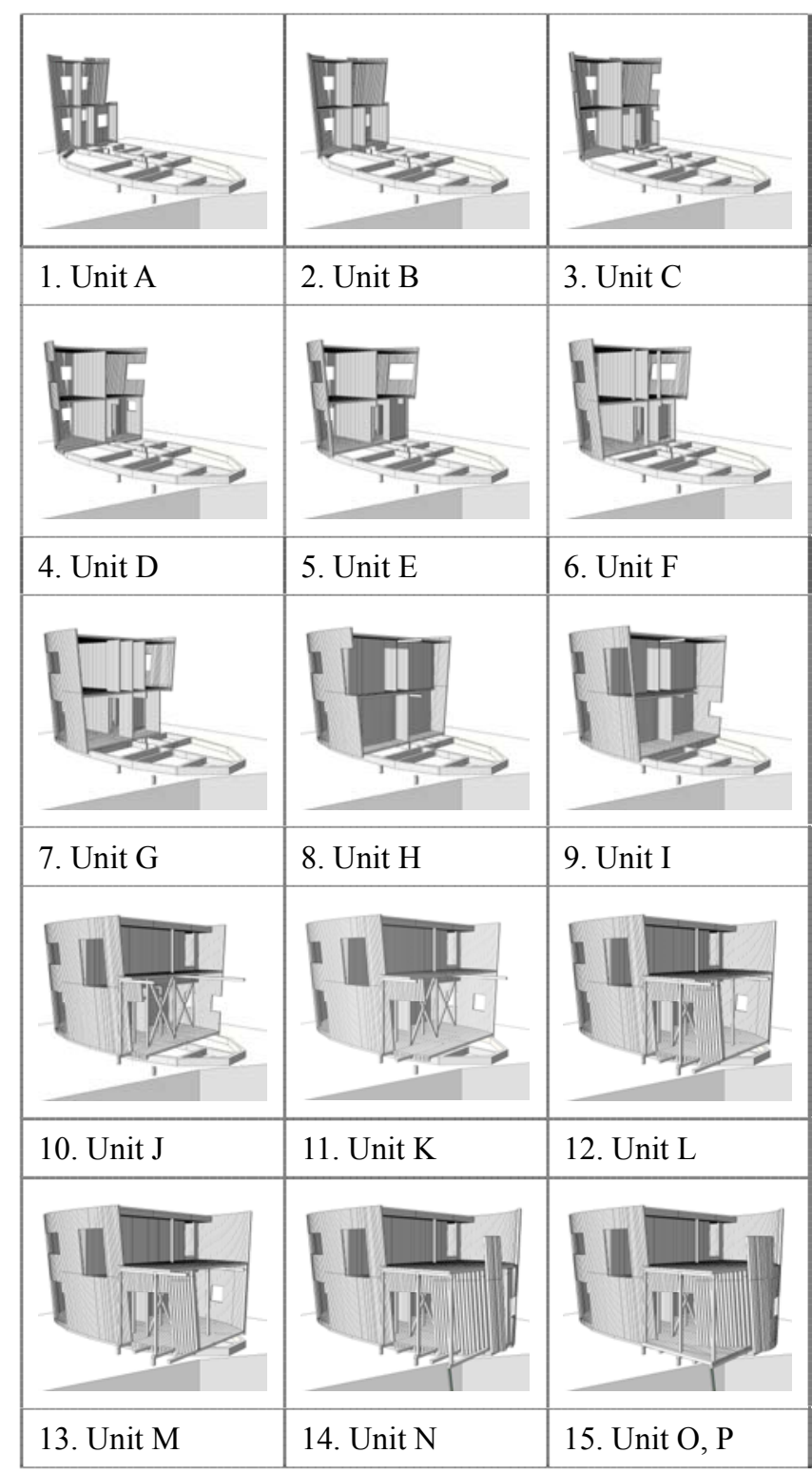

Fig. 17 Construction order of skeleton

\subsection{To create the ends of building}

In this part, we did not use dovetail joint. Unit $\mathrm{O}$ and $\mathrm{P}$ were created by many solid V shapes, which were used thinned out Japanese cedar $100 \mathrm{~mm} \times 30 \mathrm{~mm}$. We used length of lumbers to arrange solid $\mathrm{V}$ shapes (sets). We used screws and construction glue to connect each set to skeleton one by one.

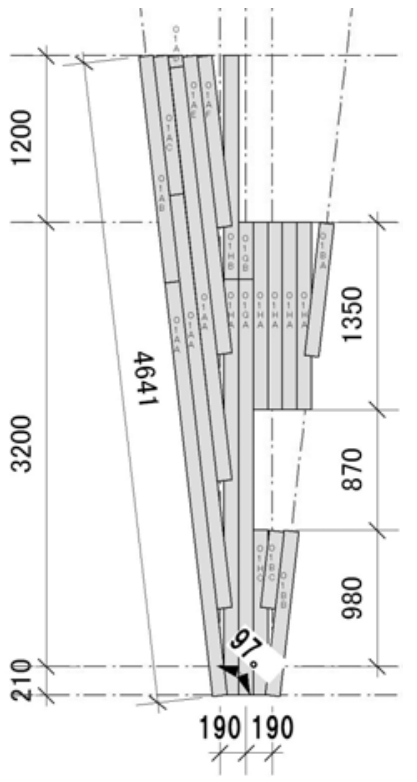

Set $\mathrm{O} 1$

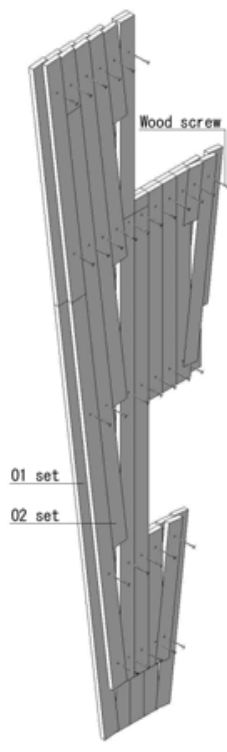

Set $\mathrm{O} 1$ and

Set $\mathrm{O} 2$

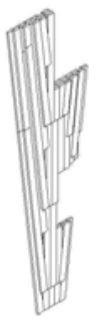

Unit O

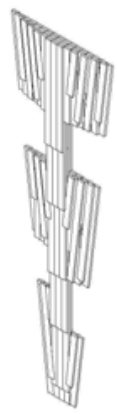

Unit P
Fig. 18 Create the ends of building's method

\section{CONCLUSIONS}

By applying the new construction method, we found that Japanese cedar has a potential value as main structure material. In this study, we developed a study for designing arc wooden house. For the future, we will study how to design for other shape or a larger space for wooden house.

\section{REFERENCES}

[1]Saji,T. and Taiji, M., "Construction methods", Rikogakusha Publishing Co.,Ltd, pp.23, 2005.

[2] Mitsumoto, A., "Demonstrative Study on Development of a Method for Reusable Wall Structure Made of Thinned Out Japanese Cedar", AIJ Kyushu chapter Architectural Research Meeting 45th (3), pp. 369-372, 2006.

[3] Kuroki, T., "Empirical Research on Development of Square Frame Wooden Structure of Thinned Cedar", Architectural Institute of Japan, pp. 296-297, 2010. 